\title{
Micro-eukaryotic diversity of the human distal gut microbiota: qualitative assessment using culture-dependent and -independent analysis of faeces
}

\author{
Pauline D Scanlan ${ }^{1}$ and Julian R Marchesi ${ }^{1,2}$ \\ ${ }^{1}$ Alimentary Pharmabiotic Centre, Department of Microbiology, University College Cork, Cork, Ireland and \\ ${ }^{2}$ School of Biosciences, Cardiff University, Cardiff, UK
}

\begin{abstract}
Molecular ecological surveys of the human gut microbiota to date have focused on the prokaryotic fraction of the community and have revealed a remarkable degree of bacterial diversity and functionality. However, there is a dearth of information on the eukaryotic composition of the microbiota, and no culture-independent sequence-based surveys of human faeces are available. Culture-independent analyses based on DNA extraction and polymerase chain reaction targeting both the total eukaryotic 18S rRNA genes and fungal internal transcribed regions (ITS), together with culture-dependent analyses of fungi, were performed on a group of healthy volunteers. Temporal analysis was also included wherever possible. Collectively, the data presented in this study indicate that eukaryotic diversity of the human gut is low, largely temporally stable and predominated by different subtypes of Blastocystis. Specific analyses of the fungal populations indicate that a disparity exists between the cultivable fraction, which is dominated by Candida sp, and cultureindependent analysis, where sequences identical to members of the genera Gloeotinia/Paecilomyces and Galactomyces were most frequently retrieved from both fungal ITS profiles and subsequent clone libraries. Collectively, these results highlight the presence of unprecedented intestinal eukaryotic inhabitants whose functional roles are as yet unknown in healthy individuals. Furthermore, differences between results obtained from traditionally employed culture-based methods and those obtained from culture-independent techniques highlight similar anomalies to that encountered when first analysing the bacterial diversity of the human faecal microbiota using culture-independent surveys.
\end{abstract}

The ISME Journal (2008) 2, 1183-1193; doi:10.1038/ismej.2008.76; published online 31 July 2008

Subject Category: microbe-microbe and microbe-host interactions

Keywords: gut microbiota; micro-eukaryotes; biodiversity; 18S rRNA analysis; DGGE; intergenic spacer analysis; Blastocystis

\section{Introduction}

The micro-ecology of the human gastrointestinal (GI) tract is a burgeoning area of scientific research with significant commercial and clinical interest. The microbial community comprises a critical part of GI functioning and plays a key role in host health and disease (Blaut and Clavel, 2007; Marchesi and Shanahan, 2007) through their roles in the development and maintenance of host physiology, immu-

Correspondence: JR Marchesi, School of Biosciences, Cardiff University, Museum Avenue, Cardiff CF10 3US, UK.

E-mail: marchesijr@cardiff.ac.uk and

PD Scanlan, Alimentary Pharmabiotic Centre, Department of Microbiology, University College Cork, Cork, Ireland.

E-mail: paulinescanlan@yahoo.co.uk

Received 21 May 2008; revised 27 June 2008; accepted 1 July 2008; published online 31 July 2008 nology and also host nutrition (Cash et al., 2006; Kelly et al., 2007). It is now apparent from the application of culture-independent techniques, including 16S rRNA gene surveys and metagenomics, that the vast majority of bacterial species present are yet to be cultivated (Suau et al., 1999; Eckburg et al., 2005). Furthermore, in addressing the microbiota of the human gut as a total community, a relative wealth of both qualitative and quantitative information is available on diverse prokaryotic populations compared with that of the eukaryotic fraction of the community (Suau et al., 1999; Eckburg et al., 2005).

Micro-eukaryotic species are ubiquitous components of various natural ecosystems, including hydrothermal environments (Gadanho et al., 2003; Lopez-Garcia et al., 2007), soil (van Elsas et al., 2000; Moon-van der Staay et al., 2006), the rumen 
(Ranilla et al., 2007) and food and beverage communities (Romano et al., 2003; Fleet, 2007; Quiros et al., 2008). In these environments, eukaryotes interact with other microbes to form complex communities that play primary roles in both ecosystem structure and function (Fleet, 1999, 2003; Lopez-Garcia et al., 2007). The first cultureindependent analysis of the fungal community populating a mammalian intestine revealed an unprecedented diversity and abundance of fungal species in the murine GI tract (Scupham et al., 2006). 18S rRNA gene analysis identified the presence of fungal species in the murine gut belonging to nine different taxonomic clusters, including Ascomycota, Basidiomycota, Mucorales and Scleroderma, and quantitative analysis indicated that fungi account for approximately $2 \%$ of the total community present in caecal biofilms. The findings of this study are of great interest to human microbial ecology from both diversity and functional perspectives and provide further impetus for the work presented in this paper. In addition, mouse models are routinely applied to address questions pertaining to human nutrition, health and drug metabolism, and, therefore, any similarities or differences that exist between the human and murine gut are of significant interest to GI research.

Many culture-dependent studies on the eukaryotes inhabiting different human niches have readily isolated yeasts, such as Candida sp, from the mouth, fingernail, toenail and rectum of healthy hosts (Kam and $\mathrm{Xu}, 2002$; Song et al., 2005). However, culture-independent surveys of eukaryotic populations of the human GI tract are negligible and are perhaps limited to one publication with no sequence data reported (Kuhbacher et al., 2006). As such, a requirement to characterize this community is apparent, and the primary aim of this study was to analyse the micro-eukaryotic inhabitants of the human intestinal tract to gain an insight into the diversity of eukaryotic species in the intestinal tracts of a cohort of healthy individuals.

\section{Materials and methods}

\section{Sample collection}

Faecal samples were collected from 17 healthy individuals and frozen immediately at $-80^{\circ} \mathrm{C}$. Faecal samples are largely representative of the microbial community in the human distal colon. Eight individuals were sampled once and nine individuals were sampled over varying time points from 8 weeks to 3 years. An overview of the participants is provided in Table 1. A broad range of age groups was analysed, and individuals representing each decade of the age groups from 20 to 60 years were sampled along with a comparable female-to-male ratio (10:7). Fifteen individuals were born and raised in Ireland, and two individuals M2 and M3 were born and raised in the United Kingdom. No individuals analysed in this study had travelled extensively or lived in a third world or developing country. In addition, for individuals who were sampled temporally, the samples obtained were evenly distributed over the time period studied.

\section{DNA extraction from human faecal samples}

Three different DNA extraction methods were tested to ensure complete extraction of all representative DNAs and minimize bias (see Supplementary Table S1). DNA extractions were performed using Method A.

Method A. Total DNA was extracted from faecal samples using a combination of physical and chemical lyses, followed by consecutive precipitation and cleaning steps to remove any polymerase chain reaction (PCR) inhibitors for subsequent downstream application. A total of $250 \mathrm{mg}$ of faecal sample was placed in a $2 \mathrm{ml}$ tube containing a $200 \mathrm{mg}$ mixture of $0.1,0.5$ and $2 \mathrm{~mm}$ zirconium beads, $500 \mu \mathrm{l}$ of $10 \mathrm{mM}$ phosphate buffer (pH 7.4), $500 \mu \mathrm{l}(10 \% \mathrm{w} / \mathrm{v})$ sodium dodecyl sulphate and $\sim 400 \mu \mathrm{l}$ phenol: chloroform (1:1). Alternate bead beating at 3200 r.p.m. per $60 \mathrm{~s}$ and cooling on ice for 10 min were carried out three times, with a final centrifugation of the lysed suspension for $10 \mathrm{~min}$ at 16000 gav. Three additional phenol:chloroform extractions were performed and DNA was then collected by centrifugation following precipitation on ice using 0.7 volumes of isopropanol. DNA was resuspended in $10 \mathrm{~mm}$ phosphate buffer and further cleaned using $3 \mathrm{M}$ sodium acetate and ethanol precipitation on ice. DNA was collected by centrifugation for $10 \mathrm{~min}$ at 16000 gav and the nucleic acid pellet was washed with $1 \mathrm{ml}$ of ice-cold $70 \%$ ethanol and then air-dried for $5 \mathrm{~min}$ before resuspending it in $200 \mu$ l of $10 \mathrm{mM}$ phosphate buffer $(\mathrm{pH}$ 7.4). Prior to PCR and to increase the efficiency of amplification, $100 \mu \mathrm{l}$ of DNA was further cleaned using saturated ammonium acetate and chloroform followed by ethanol precipitation and subsequent centrifugation to collect the nucleic acid pellet. DNA was resuspended in $50 \mu \mathrm{l}$ of distilled water, added to $150 \mu \mathrm{l}$ of Chelex $(10 \% \mathrm{w} / \mathrm{v}$ distilled water) and heat-treated for $5 \mathrm{~min}$ at $37^{\circ} \mathrm{C}$ and $5 \mathrm{~min}$ at $95^{\circ} \mathrm{C}$, and then cooled to $4{ }^{\circ} \mathrm{C}$; the supernatant was removed and stored at $-20{ }^{\circ} \mathrm{C}$ until further use. DNA was visually assessed on $1 \%$ agarose containing ethidium bromide $\left(0.25 \mathrm{mg} \mathrm{ml}^{-1}\right)$ and $0.5 \times \mathrm{TAE}$ buffer (Sambrook et al., 2000) with an applied voltage of $5 \mathrm{~V} \mathrm{~cm}^{-1}$. DNA was visualized by UV illumination (302 $\mathrm{nm}$ ), and DNA concentration was determined using the Nanodrop spectrophotometer.

\section{PCR of $18 S$ rRNA genes and fungal internal transcribed} regions

Polymerase chain reaction mixtures $(50 \mu \mathrm{l})$ contained $1 \times$ buffer (20 mM Tris (pH 8.4), $50 \mathrm{mM} \mathrm{KCl)}$, $3 \mathrm{mM} \mathrm{MgCl}_{2}, 200 \mu \mathrm{M}$ of each dNTP, $1.25 \mathrm{U}$ of Taq 
Table 1 Overview of participants

\begin{tabular}{|c|c|c|c|c|}
\hline Subject code & Age & Sex & Medical history & $\begin{array}{l}\text { No. of samples obtained and } \\
\text { time period over which samples } \\
\text { were collected }\end{array}$ \\
\hline M1 & 54 & M & Treated for diverticulitis & $N=3,12$ weeks \\
\hline M2 & 25 & $\mathrm{M}$ & None & $N=3,12$ weeks \\
\hline M3 & 40 & $\mathrm{M}$ & $\begin{array}{l}\text { None, history of } \\
\text { intermittent antibiotic usage }\end{array}$ & $N=3,12$ weeks \\
\hline M4 & 26 & $\mathrm{M}$ & None & Once \\
\hline M5 & 26 & $\mathrm{M}$ & None & $N=6,2$ years \\
\hline M6 & 62 & $\mathrm{M}$ & None & Once \\
\hline M7 & 59 & $\mathrm{M}$ & None & Once \\
\hline F1 & 38 & $\mathrm{~F}$ & None & $N=6,3$ years \\
\hline F2 & 28 & $\mathrm{~F}$ & None & $N=6,2$ years \\
\hline F3 & 54 & $\mathrm{~F}$ & None & $N=3,12$ weeks \\
\hline $\mathrm{F} 4$ & 27 & $\mathrm{~F}$ & None & $N=4,3$ years \\
\hline F5 & 28 & $\mathrm{~F}$ & None & Once \\
\hline F6 & 23 & $\mathrm{~F}$ & None & $N=3,6$ months \\
\hline F7 & 61 & $\mathrm{~F}$ & None & Once \\
\hline F8 & 64 & $\mathrm{~F}$ & None & Once \\
\hline F9 & 63 & $\mathrm{~F}$ & None & Once \\
\hline F10 & 65 & $\mathrm{~F}$ & None & Once \\
\hline
\end{tabular}

Abbreviations: F, female; M, male.

polymerase (Invitrogen, Paisley, UK) and $10 \mathrm{pmol}$ of each primer. Bovine serum albumin and appropriately diluted DNA (80-100 ng) was added to the final PCR. The PCR program for primers Euk1a and 516r and 516r-GC (Supplementary Table S1) consisted of an initial denaturation at $94{ }^{\circ} \mathrm{C}$ for $5 \mathrm{~min}$, followed by 35 cycles of denaturation at $94{ }^{\circ} \mathrm{C}$ for $30 \mathrm{~s}$, annealing at $55^{\circ} \mathrm{C}$ for $40 \mathrm{~s}$, extension at $72{ }^{\circ} \mathrm{C}$ or $60 \mathrm{~s}$ and a final extension of $5 \mathrm{~min}$ at $72^{\circ} \mathrm{C}$. $18 \mathrm{~S}$ rRNA gene PCR products were obtained from all individuals in this study using the primers Euk1a and 516r. The PCR program for primers ITS1F and ITS4R (Supplementary Table S1) consisted of an initial denaturation at $95{ }^{\circ} \mathrm{C}$ for $5 \mathrm{~min}$, followed by 35 cycles of denaturation at $94{ }^{\circ} \mathrm{C}$ for $30 \mathrm{~s}$, annealing at $50{ }^{\circ} \mathrm{C}$ for $30 \mathrm{~s}$, extension at $72{ }^{\circ} \mathrm{C}$ for $60 \mathrm{~s}$ and a final extension of $5 \mathrm{~min}$ at $72^{\circ} \mathrm{C}$. Fungal internal transcribed region (ITS) PCR products were generated from 14 of the 17 individuals in this study using the primer pair ITS1F and ITS4R.

\section{Denaturing gradient gel electrophoretic analysis and band excision}

18S rRNA gene PCR products were separated according to the specifications of Muyzer et al. (1993) using the DCODE system (Bio-Rad Laboratories, Hemel Hempstead, UK) with the following modifications: polyacrylamide gels (dimensions: $200 \times 200 \times 1 \mathrm{~mm}^{3}$ ) consisted of $8 \% \mathrm{v} / \mathrm{v}$ polyacrylamide (37.5:1 acrylamide/bisacrylamide) and $0.5 \times$ TAE. The final denaturant gradient for primer pair Euk1A and 516r-GC was optimized to 5-35\%. Prior to polymerization of the denaturing gel, a stacking gel without denaturants was added. Electrophoresis was performed for $16 \mathrm{~h}$ at $85 \mathrm{~V}$ in $0.5 \times$ TAE buffer at a constant temperature of $60{ }^{\circ} \mathrm{C}$. Gels were stained with SybrGold according to the manufacturer's instructions. All bands present on 18S rRNA gene denaturing gradient gel electrophoretic profiles were excised using a gel spot extractor pipette and DNA was eluted in PCR grade water for $30 \mathrm{~min}$ at room temperature. A volume of $1 \mu \mathrm{l}$ was used as template DNA in PCR, as previously described, using primers Euk1A and 516r-GC. The resulting product was resolved on a gel with the original sample to identify and ensure the correct band selection for sequencing. PCR products were cleaned using the Qiagen QIAquick PCR cleanup kit according to the manufacturer's instructions prior to sequencing.

Fungal internal transcribed spacer analysis

Fungal intergenic spacer PCR products were separated using $4 \%$ polyacrylamide gels (dimensions: $160 \times 215 \times 1 \mathrm{~mm}^{3}$ ) and electrophoresis was performed for $4 \mathrm{~h}$ at a constant voltage of $180 \mathrm{~V}$. All gels were stained with SybrGold (Molecular Probes, Paisley, UK) according to the manufacturer's instructions. Bands of interest were excised and analysed as previously outlined for DGGE band excision.

Clone library construction and analysis

For the construction of clone libraries, PCR cycle numbers were reduced to 25 to minimize any bias imposed by the $\mathrm{C}_{\mathrm{O}} \mathrm{T}$ effect (Mathieu-Daude et al., 1996) or preferential DNA amplification. For each clone library, four PCR reactions on the same sample were pooled and cleaned using the Qiagen PCR cleanup kit prior to clone library construction. PCR products were transformed into Escherichia coli cells using TOPO XL PCR cloning kit (Invitrogen, Dublin, Ireland) according to the manufacturer's 
instructions. 18S rRNA gene clone libraries were constructed from PCR products generated using the primer set Euk1a and $516 \mathrm{r}$ as per the protocol previously outlined for PCR of $18 \mathrm{~S}$ rRNA genes. A total of 11 libraries were constructed and 36 randomly selected clones from each $18 \mathrm{~S}$ rRNA gene library were selected for sequencing. Fungal intergenic spacer clone libraries were constructed using PCR products generated using the primer set ITS1F and ITS4R. A total of 11 libraries were generated and, owing to natural size and sequence variation of fungal ribosomal intergenic spacer regions, 48 clones from each library were picked, re-amplified by PCR and the products were size checked by PCR on $1.5 \%$ agarose gels prior to plasmid preparation (Qiagen mini prep kit) and sequencing.

\section{Bionumerix gel analysis}

To extrapolate meaningful data from the DGGE and fungal internal transcribed spacer analysis gel profiles, the Gel Compar function of the Bio Numerics software programme (Applied Maths, St. Martens-Latem, Belgium) was used to calculate similarities between samples from individuals over time (intra-individual similarity/individual temporal stability) and between samples from different individuals (inter-individual similarity). The similarities were determined by calculating similarity indices based on the DICE similarity coefficient and the unweighted pair-group method using arithmetic averages (UPGMA). The DICE coefficient is also referred to as Sorenson's pair-wise similarity coefficient $\left(C_{\mathrm{s}}\right)$ and is commonly used to compare species composition of different ecosystems.

\section{Fungal culturing and identification}

Faecal samples were serially diluted and fivefold dilutions were spread-plated in triplicate on Sabouraud dextrose agar, potato dextrose agar and malt agar supplemented with chloramphenicol $\left(40 \mu \mathrm{g} \mathrm{ml}^{-1}\right)$ and kanamycin $\left(50 \mu \mathrm{g} \mathrm{ml}^{-1}\right)$. The plates were incubated both aerobically and anaerobically for $48 \mathrm{~h}$ at $37^{\circ} \mathrm{C}$ and counted. Random colonies and any colonies exhibiting different morphologies were restreaked to obtain pure cultures. DNA extraction from pure fungal cultures was performed as per the protocol described by Gadanho et al. (2003). In brief, $200 \mathrm{mg}$ of overnight spread-plate cultures was suspended in a $2 \mathrm{ml}$ tube containing $200 \mu \mathrm{l}$ volume of $500 \mu \mathrm{m}$ of glass beads and $500 \mu \mathrm{l}$ of lysing buffer (50 mM Tris, $250 \mathrm{~mm} \mathrm{NaCl,} 50 \mathrm{~mm}$ EDTA, $0.3 \% \mathrm{w} / \mathrm{v}$ sodium dodecyl sulphate ( $\mathrm{pH} 8)$ ). After a 2 min bead beat step, samples were incubated at $65^{\circ} \mathrm{C}$ for $1 \mathrm{~h}$. Suspensions were then centrifuged at 16000 gav for $10 \mathrm{~min}$. The collected supernatant was diluted to 1:100 and $2 \mu \mathrm{l}$ used in a $50 \mu \mathrm{l}$ PCR, as outlined for both primer sets Euk1a and 516r and ITS1 and ITS4. The PCR products were cleaned as previously outlined prior to sequencing. Ninety-five PCR products from pure culture isolates were generated for analysis.

Bioinformatic sequence analysis and phylogenetic tree construction

All sequences from pure culture PCR products, DGGE and ITS extracted bands and clone libraries were analysed using the tBLASTn (Altschul et al., 1990) functions for nucleotide identification. Phylogenetic trees were constructed with unambiguously aligned nucleotide sequences using the MEGA4 software package (Tamura et al., 2007). The evolutionary history was inferred using the neighbour-joining method (Saitou and Nei, 1987) from nonredundant $18 \mathrm{~S}$ rRNA gene sequences obtained from DGGE band excision and clone libraries. The bootstrap consensus tree inferred from 500 replicates is taken to represent the evolutionary history of the taxa analysed (Archie and Felsenstein, 1993). The percentage of replicate trees in which the associated taxa clustered together in the bootstrap test (500 replicates) is shown next to the branches. The tree is drawn to scale, with branch lengths expressed in the same units as the evolutionary distances used to infer the phylogenetic tree. The evolutionary distances were computed using the maximum composite likelihood method (Tamura et al., 2004) and are expressed as the number of base substitutions per site. All positions containing gaps and missing data were eliminated from the data set ('Complete deletion' option). Owing to partial sequence reads obtained from DGGE band excision sequencing, 394 nucleotides were included in the final data set.

\section{Accession numbers}

Accession numbers for 18S rRNA genes and fungal ITS sequences retrieved in this study are available from EMBL database numbers AM992460-AM992473 and AM998784-AM998792, respectively.

\section{Results and discussion}

A paucity of information exists on the incidence and diversity of eukaryotes in the GI tract of humans, and the primary aim of this paper was to outline suitable culture-independent methodologies that address this concern. As such, appropriate DNA extraction and PCR methods were optimized (see Supplementary Table S1) and the composition of the microeukaryotic fraction of the human gut microbiota was determined using a three-tiered experimental design; DNA extraction followed by (1) PCR amplification and analyses of $18 \mathrm{~S}$ rRNA genes to survey total eukaryotes, (2) PCR amplification and analyses of fungal ITS regions to assess the fungal community and finally (3) determination of the congruency of results between cultivation-independent and -dependent techniques through the comparative analysis of fungal 18S rRNA genes and ITS regions. 
Blastocystis is a common and stable feature

of the human healthy distal colon

Denaturing gradient gel electrophoretic analysis of 18S rRNA gene PCR products indicates that the diversity of eukaryotes in the human intestinal tract is low (between one and three bands per individual) and relatively stable over time (see Figure 1). Software analysis of generated DGGE profiles shows inter-individual variation and similarity, and variability with respect to intra-individual temporal stability (see Figure 1). Band excision and analysis, supported by clone library analysis, revealed that Blastocystis sp were the most common eukaryotes recovered (14/17 individuals analysed), with fungal sequences infrequently recovered as well. Although Blastocystis was the dominant eukaryote common to all individuals analysed, with three exceptions, comparative DGGE gel and sequence analysis, followed by phylogenetic tree construction, indicated that Blastocystis sp present between individuals were widely diversified (see Figure 2). Furthermore, temporal analysis indicated that when present in DGGE profiles, Blastocystis sp were the dominant and constant feature of all time points analysed.

Blastocystis sp are obligate anaerobes of controversial epidemiological status and are phylogenetically placed within the Stramenopiles (Silberman et al., 1996), a heterogeneous taxonomic group that includes uni- and multicellular protists, such as brown algae and diatoms (Patterson, 1994). Although these are routinely cited as a common human intestinal parasite or pathogen and have been suggested as an aetiological agent in many GI illness, including diarrhoea, inflammatory bowel disease and irritable bowel syndrome (Giacometti et al., 1999; Yakoob et al., 2004; Stark et al., 2007), it is believed that the potential pathogenicity of Blastocystis is subtype-dependent (Kaneda et al., 2001; Tan et al., 2006). Genetic and polymorphic variations of Blastocystis are well reported in the literature and classification schemes based on $18 \mathrm{~S}$ rRNA genes and elongation factor genes have been used to infer phylogenetic relationships and discrete lineages (Ho et al., 2000; Abe, 2004; Yoshikawa et al., 2004), and the phylogenetic tree constructed from Blastocystis sequences obtained from different individuals analysed in this study falls into distinct phylogenetic clades or subtypes that have been previously defined (Arisue et al., 2003; Stensvold et al., 2007a). The majority of individuals harboured Blastocystis sp that cluster with subtypes II, III and IV, and interestingly no sequences representing Blastocystis sp from subtypes V, VI and VII were obtained. An interesting observation from both DGGE and phylogenetic tree analyses shows that four out of the six individuals analysed from the $\geqslant 60$ years age group (F7, F8, F9 and M7) clustered together in DGGE profiles and with subtype III species, whereas the two other members from this age group clustered with subtype II (M6 and F10). In

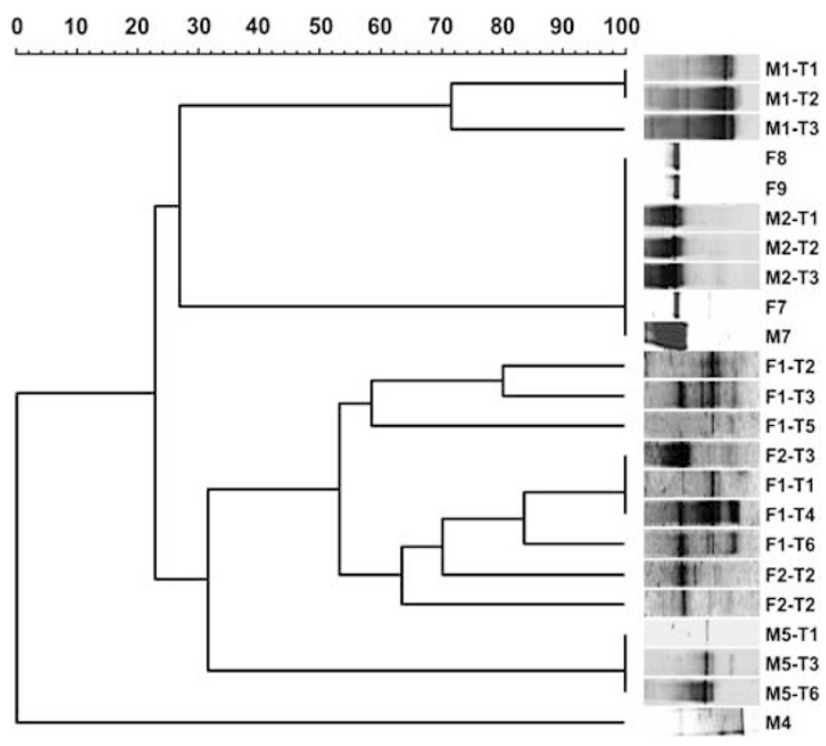

Figure 1 Denaturing gradient gel electrophoretic profile analysis. DICE correlation coefficients yielded the calculated similarity indexes (expressed as percentages) of DGGE profiles generated from a selection of different individuals using the eukaryotic primer pair Euk1a and Euk516r-GC. The dendrogram is a statistically optimal representation of the similarities between DGGE profiles based on the matrix of DICE correlation coefficients and UPGMA. The code for each individual is outlined in Table 1 and the letter $\mathrm{T}$ followed by a number present after the code represents the time point analysed where applicable. This figure highlights both inter-individual variation and similarities and variations in intra-individual temporal stability are evident.

addition, the three individuals that clustered with group IV were all under the age of 28 years. Otherwise, no clear pattern could be determined with respect to Blastocystis incidence across individuals and the results presented here largely indicate that sex is not a factor in clustering, as both males and females are represented when present.

It is apparent from previous studies and the data presented here that many Blastocystis sp are commonly shared across human and animal species, which indicates low host specificity and a versatile genome, with a capacity for survival in the potentially harsh GI environments of wide range of hosts (Tan, 2004). The manner by which humans acquire Blastocystis sp is still uncertain, as many modes of transmission have been proposed, including human-human and animal-human (Yan et al., 2006). M1 and F3, a couple married for 32 years, hosted different Blastocystis sp that clustered with subtypes I and II, respectively. In addition, their daughter (F4) did not have any Blastocystis sp present on analyses, which might indicate that human-human transmission is not important, but Blastocystis might be more likely acquired from an environmental source (Karanis et al., 2007).

A high incidence of Blastocystis is usually associated with poor sanitation and surveys have typically focused on developing countries (Ostan 


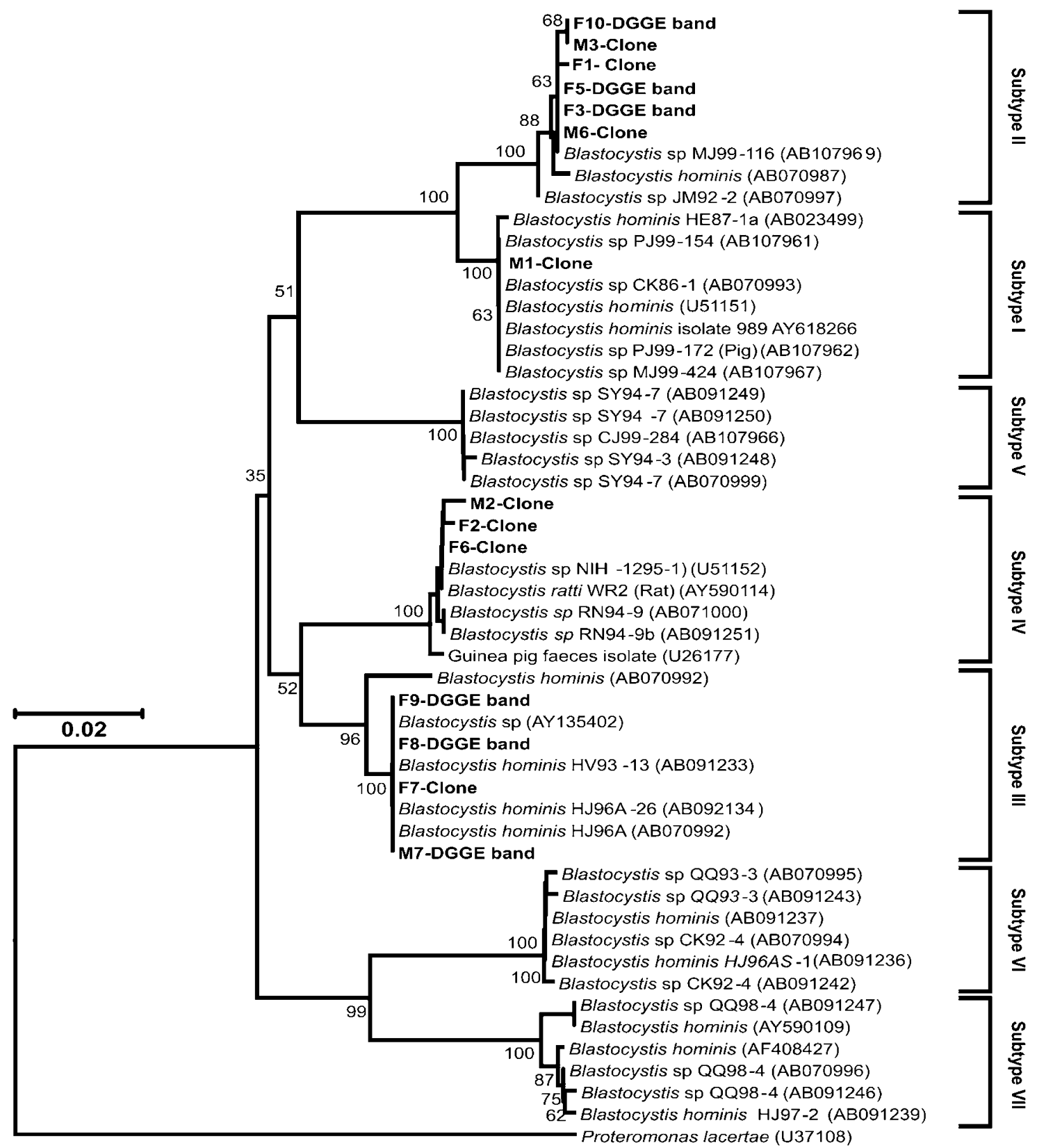

Figure 2 Phylogenetic tree of partial 18S rRNA gene sequences of Blastocystis sp.

et al., 2007). The considerable variation in Blastocystis incidence among broad and disparate human populations is likely owing to the specific diagnostic procedures employed (Stensvold et al., 2007a, b). Previous analysis of individuals from developed countries has shown prevalence rates of $0.5 \%$ in Japan (Horiki et al., 1997) and up to $23 \%$ in America (Amin, 2002); however, it is most probable that the high numbers of individuals positive for Blastocystis $(82 \%)$ presented in this study may be as a result of the increased sensitivity of PCR-based assays over traditional methods (Stensvold et al., 2007b). With respect to the data presented here, the incidence, dominance and temporal stability, together with inter-individual similarity and diversity, of Blasto- cystis in this study of non-symptomatic healthy individuals from a developed Western country are of significant interest and require further investigation. As such, research should focus on the clinical relevance of this eukaryote and on establishing whether certain Blastocystis sp have functional roles in the gut of asymptomatic individuals.

Three individuals analysed using DGGE and clone library analysis of the 18S rRNA gene differed from the Blastocystis trend; in one individual (M4), Entamoeba coli was identified as the only species present. Individuals (F4 and M5) hosted a fungal species with $100 \%$ 18S rRNA gene sequence identity to both Verticillium leptobactrum (AB214657)/Verticillium insectorum (AB214657) 
and Paecilomyces fumosoroseus (AB086629). This sequence was present at all time points for both individuals. In addition, individual F4 was positive for Saccharomyces cerevisiae over a 3-year period (these latter two results were supported by ITS profile and clone library sequence data where sequences $100 \%$ identical to both Gloeotinia temulenta (DQ235697) and P. fumosoroseus (AB086629) were also recovered (see Table 2). 18S rRNA gene sequences homologous to the fungi Aspergillus and Rhizochaete, and the insect genus Mydas, were retrieved from one individual (F2) who was analysed over a 2-year period. These sequences were only retrieved from single time points and not temporally, which could indicate that there is also a transient nature to the composition of the microeukaryotic GI community, a feature similar to the fungal ITS temporal analysis. As a method to characterize both similarities and differences of eukaryotic communities, the usefulness of the DGGE method is best suited to temporal analyses of individuals. Although DGGE was also able to identify true similarities between different individuals, some individuals that clustered together on gel analysis had different band products upon sequence analysis (see Figure 2). Therefore, sequence analyses of PCR products and DGGE bands are required to resolve any potential ambiguities when applying the techniques outlined in this study.

Fungal diversity of human intestinal tract is low, relatively stable and incongruent between culture and culture-independent analysis

Fungal ITS PCR products were obtained from 14 out of 17 individuals analysed in this study. The diversity of fungi in the human intestinal tract is low (one to three bands per individual) and both fungal ITS profile and sequence analyses demonstrated both inter-individual similarity and variation across the group of individuals (see Figure 3 and Table 2). Temporal analysis of ITS profiles showed that each individual's profile was largely stable over time with

Table 2 Results from fungal cultivation and cultivation-independents analysis of health subjects

\begin{tabular}{|c|c|c|c|}
\hline Subject code & $\begin{array}{l}\text { Mean fungal } \\
\text { counts } C F U g^{-1} \\
\left(37^{\circ} \mathrm{C}\right)\end{array}$ & $\begin{array}{l}\text { Pure-culture isolate } \\
\text { classification (closest } \\
\text { relative on database) }\end{array}$ & $\begin{array}{l}\text { Fungal ITS sequence classification recovered from } \\
\text { profiles and clone libraries (closest relative on } \\
\text { database) }\end{array}$ \\
\hline M1 & $6.0 \times 10^{2}$ & $\begin{array}{l}\text { Candida parapsilosis } \\
\text { (EF152414) }\end{array}$ & $\begin{array}{l}\text { Gloeotinia temulenta (DQ235697)/Paecilomyces } \\
\text { fumosoroseus (AB086629) and Cephalosporium sp } \\
\text { JS2015 (AM176722) }^{\mathrm{a}}\end{array}$ \\
\hline M2 & $1.9 \times 10^{4}$ & $\begin{array}{l}\text { Candida parapsilosis } \\
\text { (EF152414) }\end{array}$ & $\begin{array}{l}\text { Gloeotinia temulenta (DQ235697)/Paecilomyces } \\
\text { fumosoroseus (AB086629) and Psathyrella } \\
\text { candolleana (DQ093736) }\end{array}$ \\
\hline M3 & $5.7 \times 10^{2}$ & $\begin{array}{l}\text { Candida parapsilosis } \\
\text { (EF152414) }\end{array}$ & Saccharomyces cerevisiae (AB280540) \\
\hline M4 & ND & NA & No PCR signal \\
\hline M5 & $1.1 \times 10^{3}$ & $\begin{array}{l}\text { Candida parapsilosis } \\
\text { (EF152414) }\end{array}$ & $\begin{array}{l}\text { Gloeotinia temulenta (DQ235697)/Paecilomyces } \\
\text { fumosoroseus (AB086629), Ceratobasidium sp } \\
\text { (DQ278930) }^{\mathrm{a}} \text { and Aspergillus versicolor (AJ937752) }\end{array}$ \\
\hline M6 & ND & NA & $\begin{array}{l}\text { Galactomyces geotrichum (DQ668351) and } \\
\text { Psathyrella candolleana (AF345810) }\end{array}$ \\
\hline M7 & ND & NA & $\begin{array}{l}\text { Galactomyces geotrichum (DQ668351) and } \\
\text { Penicillium roquefortii strain FRR } 849 \text { (AY373929) }\end{array}$ \\
\hline F1 & $6.1 \times 10^{5}$ & $\begin{array}{l}\text { Candida parapsilosis } \\
\text { (EF152414) }\end{array}$ & Galactomyces sp BPY-54 (DQ286062) \\
\hline F2 & $1.1 \times 10^{4}$ & $\begin{array}{l}\text { Candida parapsilosis } \\
\text { (EF152414) }\end{array}$ & $\begin{array}{l}\text { Gloeotinia temulenta (DQ235697)/Paecilomyces } \\
\text { fumosoroseus (AB086629) }\end{array}$ \\
\hline F3 & $1.0 \times 10^{3}$ & $\begin{array}{l}\text { Candida albicans ATCC } \\
10231\end{array}$ & $\begin{array}{l}\text { Gloeotinia temulenta (DQ235697)/Paecilomyces } \\
\text { fumosoroseus (AB086629) and Saccharomyces } \\
\text { cerevisiae (AB212259) }\end{array}$ \\
\hline F4 & $1.0 \times 10^{2}$ & $\begin{array}{l}\text { Candida parapsilosis } \\
\text { (AY520248) }\end{array}$ & $\begin{array}{l}\text { Gloeotinia temulenta (DQ235697)/Paecilomyces } \\
\text { fumosoroseus (AB086629) and Saccharomyces } \\
\text { cerevisiae (AM90040) }\end{array}$ \\
\hline F5 & $2.0 \times 10^{3}$ & $\begin{array}{l}\text { Candida albicans ATCC } \\
10231\end{array}$ & $\begin{array}{l}\text { Saccharomyces cerevisiae (AM90040) and Candida } \\
\text { albicans ATCC } 10231\end{array}$ \\
\hline F6 & $1.4 \times 10^{3}$ & $\begin{array}{l}\text { Candida parapsilosis } \\
\text { (AY520248) }\end{array}$ & $\begin{array}{l}\text { Gloeotinia temulenta (DQ235697)/Paecilomyces } \\
\text { fumosoroseus (AB086629) }\end{array}$ \\
\hline F7 & ND & NA & No PCR signal \\
\hline F8 & $1.5 \times 10^{4}$ & $\begin{array}{l}\text { Candida albicans ATCC } \\
10231 \text { (EU266569) }\end{array}$ & No PCR signal \\
\hline F9 & $1.6 \times 10^{6}$ & $\begin{array}{l}\text { Candida albicans } \\
\text { ATCC:10231 (EU266569) }\end{array}$ & $\begin{array}{l}\text { Candida albicans ATCC: } 10231 \text { (EU266569) and } \\
\text { Galactomyces geotrichum (DQ668351) }\end{array}$ \\
\hline F10 & ND & NA & Cf. Acremonium sp FSU2858 (AY633563) \\
\hline
\end{tabular}

Abbreviations: NA, not applicable; ND, not detected.

${ }^{a}$ These fungal species were found at single time points for temporally analysed individuals. 
1190

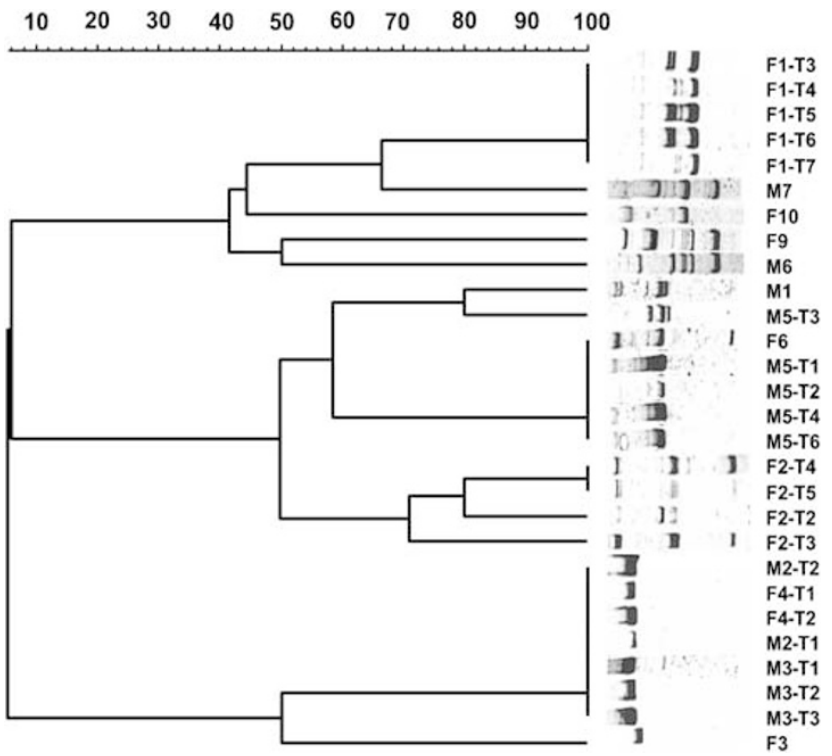

Figure 3 Fungal internal transcribed spacer analysis (FITSA) profile analysis. Example of FITSA gel cluster analysis highlighting inter-individual variation, and similarities with intraindividual temporal stability are also evident. DICE correlation coefficients yielded the calculated similarity indexes (expressed as percentages on horizontal bar) of gel profiles generated from different individuals using the eukaryotic primer pair ITS1F and ITS4R. The code outlined in Table 1 and the numbers present after the code represent the time point analysed, where applicable. The dendrogram is a statistically optimal representation of the similarities between gel profiles based on the matrix of DICE correlation coefficients and UPGMA and analysis was performed using the Gel Compar software programme.

the occasional detection of transient fungal species (see Figure 3). Table 2 describes the different ITS sequence recovered from both fungal internal transcribed spacer analysis gel profiles and ITS libraries. The most commonly recovered species retrieved from seven individuals was $100 \%$ identical to $G$. temulenta (DQ235697)/P. fumosoroseus (AB086629). Temporal analysis of individuals indicated that, when present, this fungal species was a constant feature of all time points analysed. Galactomyces was also recovered from four individuals and, when present, was also a constant feature of all time points analysed. In addition, this species was also recovered from 18S rRNA gene DGGE analysis of one individual (F1). Many other species, including likely food borne fungi, such as Penicillium roquefortii, were retrieved at single time points using ITS clone library and gel analysis. S. cerevisiae was also recovered from cultivation-independent analysis, but was not recovered from plates, which may be owing to initial freezing of samples, the presence of temperature-sensitive strains or the application of suboptimal cultivation methods for the isolation of $S$. cerevisiae.

There was considerable variation in the total counts of viable fungi isolated at $37^{\circ} \mathrm{C}$ from different individuals ranging from 0 up to $1.45 \times 10^{6} \mathrm{CFUg}^{-1}$ of faeces from all individuals analysed. Uniform colony morphologies were evident on plates and
18S rRNA gene and ITS sequence analyses revealed that this uniform morphological type present across individuals was most closely related to Candida. Of particular interest is the lack of congruency between cultivation and cultivation-independent analysis. It is generally believed that Candida sp are the dominant fungal species in the human gut. However, the fact that Candida sp sequences were never detected in either 18S rRNA gene DGGE analysis and only recovered from the two ITS gel profiles indicate that they are not in fact the dominant eukaryotes in the distal colon of healthy individuals. One of these individuals (F9) had the highest Candida counts in this study $\left(>10^{6} \mathrm{CFUg}^{-1}\right.$ of faeces), which may be the threshold of detection for these species using the cultivation-independent approaches. As such, it is possible that Candida sp cell numbers were below the threshold levels of detection for the PCR protocols outlined in this study. However, in individual F5, Candida albicans counts did not exceed $10^{3} \mathrm{CFUg}^{-1}$ of faeces and a signal was obtained by ITS-PCR; this disparity needs further work to clarify the limits of detection for the PCR. Previous studies using DGGE to characterize the micro-eukaryotic communities in food and beverages have also encountered this anomaly where yeasts isolated by culture were not represented in 18S rRNA gene DGGE profiles (Fleet, 2007). Media such as Sabouraud dextrose may provide a selective enrichment bias toward yeasts, such as Candida. Initial optimization and exploratory analysis using Sabouraud dextrose agar plates incubated aerobically at 30,20 and $12{ }^{\circ} \mathrm{C}$, isolated fungal species such as Rhodotorula mucilaginosa and Penicillium sp. These particular species were not recovered from plates incubated at $37^{\circ} \mathrm{C}$, which emphasizes the biases imposed when selecting a priori parameters required for cultivation-based analysis. In addition, the impact of freezing on faecal samples is unknown and may impact the recovery of cultivable fungi. Overall, the application of both cultivation-dependent and -independent analyses of fungal diversity within the human GI tract revealed a relatively limited range of different species across individuals compared with the diversity of fungal species present in the murine gut (Scupham et al., 2006), and also in comparison with the diversity of bacterial species present in the distal colon of healthy human hosts (Eckburg et al., 2005; Suau et al., 1999). Although a wide range of primers were tested during optimization (see Supplementary Table S1), the impact of any bias, selectivity and coverage of the primers used to generate data in this study may limit the complete characterization of all species present.

The introduction and establishment of the GI microbiota can occur from numerous sources, including contact with the environment. Genes encoding $\mathrm{pH}$, bile, anaerobic tolerance and the ability to compete for nutrients and space are necessary for competing species to survive. A ready 
source of microbial inocula includes diet, where food and beverages represent complex microbial ecosystems comprising yeasts, filamentous fungi, bacteria and their viruses. Both Candida sp and, in particular, Saccharomyces sp are routinely used in the brewing and baking industry; Galactomyces sp are routinely found in cheese microbial consortia where they are used in starter cultures (Goerges et al., 2008); and Galactomyces geotrichum has also been identified as an agent in soft drinks spoilage (Ancasi et al., 2006). As such, when fermented foods and beverages or food containing eukaryotic species are consumed on a continuous basis, they provide ready inocula for the host. Furthermore, fungal species such as $P$. fumosoroseus are commonly used as bio-control agents against economically important agricultural pests, and this may be responsible for its incidence in humans (Madsen et al., 2007). To the authors' knowledge, this is the first account of the Galactomyces, Paecilomyces and Gloeotinia genera of fungal species addressed in the context of a healthy human GI tract, and as such no reference material is available. The presence of such species in the distal colon may be a reflection of the diet and/or the environment of the individual, but the presence of these species across different individuals and over time points conceivably indicates that they are common and stable inhabitants of the healthy human intestinal tract. With this novel data, we can now begin to further investigate the roles of these species in the human distal colon.

\section{Concluding remarks}

Molecular ecological analysis of microorganisms from complex communities is an extremely difficult undertaking considering that the vast majority of both bacterial and eukaryotic species in natural environments are refractory to cultivation (Amann et al., 1990; Pace, 1997; Hugenholtz et al., 1998; Suau et al., 1999). To circumvent the requirement for laborious optimization and concurrent largescale culturing that is necessary to facilitate the complex and distinct growth requirements of eukaryotes from natural environments, culture-independent approaches are requisite to complete community diversity surveys (Edgcomb et al., 2002; Lepere et al., 2006).

Prior to this investigation, the eukaryotic members of the human gut microbial community have been primarily assessed using cultivation-based methods, and this has led to the belief that they are not widely distributed or abundant in the human microbiota (Rajilic-Stojanovic et al., 2007). This statement is indeed true for the cultivable fraction of the community, but through the application of cultivation-independent techniques, such as DNA extraction and PCR, this study provides evidence that stable eukaryotic communities are widespread in the healthy human gut. Furthermore, allochthonous species were routinely encountered during analysis of temporally sampled individuals, indicating a transient characteristic of the micro-eukaryotic community of the GI tract. Blastocystis sp and fungi identical to Gloetenia/Paecilomyces and Galactomyces are common GI inhabitants, and, when present, are stable and constant features of the micro-eukaryotic community. This raises many interesting ecological questions pertaining to micro-eukaryotes and their impact on both health and disease of the host. For example, what factors are involved in niche colonization and competition, what are their substrate requirements and what is the impact of their metabolic output and extracellular metabolite production? Does the sheer size and volume of a eukaryotic cell compared to that of a bacterial cell influence competition and interaction with other components of the GI microbiota and also the host cell? Do some GI tracts posses a bacterial community that is suppressive toward pathogenic fungi, a phenomenon seen in the soil ecosystem (Borneman and Becker, 2007)? What are the potential roles eukaryotes may play in immune stimulation and modulation; for example, the role of yeasts and the presence of anti-S-cerevisiae antibodies in Crohn's disease (Schaffer et al., 2007) and the use of certain helminths as a treatment for CD (Reddy and Fried, 2007)?

Results presented in this study highlight fungal culturing biases that are similar to the anomalies that scientists encountered when they began to investigate the bacterial fraction of the human GI microbiota (Suau et al., 1999; Hayashi et al., 2002), where readily cultivable species, such as E. coli, were overrepresented on plates. Therefore, as with bacterial culturing, it would appear that the application of traditionally used cultivation media such as Sabouraud dextrose agar for the cultivation of fungi from the human GI alone does not by itself provide an accurate account of the extant diversity. With this novel information, we can begin not only to apply different cultivation methods to the human GI tract but also design better cultivation techniques to isolate fungi, assess the functionality of Blastocystis and further investigate the long-neglected role of micro-eukaryotic species and their role in gut health.

\section{Acknowledgements}

We thank all the participants for providing samples for this study and making it possible. This research was supported by Science Foundation Ireland.

\section{References}

Abe N. (2004). Molecular and phylogenetic analysis of Blastocystis isolates from various hosts. Vet Parasitol 120: 235-242.

Altschul SF, Gish W, Miller W, Myers EW, Lipman DJ. (1990). Basic local alignment search tool. J Mol Biol 215: $403-410$. 
Amann RI, Binder BJ, Olson RJ, Chisholm SW, Devereux R, Stahl DA. (1990). Combination of 16S rRNA-targeted oligonucleotide probes with flow cytometry for analyzing mixed microbial populations. Appl Environ Microbiol 56: 1919-1925.

Amin OM. (2002). Seasonal prevalence of intestinal parasites in the United States during 2000. Am J Trop Med Hyg 66: 799-803.

Ancasi EG, Carrillo L, Benitez Ahrendts MR. (2006). Moulds and yeasts in bottled water and soft drinks. Rev Argent Microbiol 38: 93-96.

Archie JW, Felsenstein J. (1993). The number of evolutionary steps on random and minimum length trees for random evolutionary data. Theor Popul Biol 43: $52-79$.

Arisue N, Hashimoto T, Yoshikawa H. (2003). Sequence heterogeneity of the small subunit ribosomal RNA genes among Blastocystis isolates. Parasitology 126: $1-9$.

Blaut M, Clavel T. (2007). Metabolic diversity of the intestinal microbiota: implications for health and disease. J Nut 137: 751S-755S.

Borneman J, Becker JO. (2007). Identifying microorganisms involved in specific pathogen suppression in soil. Annu Rev Phytopathol 45: 153-172.

Cash HL, Whitham CV, Behrendt CL, Hooper LV. (2006). Symbiotic bacteria direct expression of an intestinal bactericidal lectin. Science 313: 1126-1130.

Eckburg PB, Bik EM, Bernstein CN, Purdom E, Dethlefsen L, Sargent M et al. (2005). Diversity of the human intestinal microbial flora. Science 308: 1635-1638.

Edgcomb VP, Kysela DT, Teske A, de Vera Gomez A, Sogin ML. (2002). Benthic eukaryotic diversity in the Guaymas Basin hydrothermal vent environment. Proc Natl Acad Sci USA 99: 7658-7662.

Fleet GH. (1999). Microorganisms in food ecosystems. Int J Food Microbiol 50: 101-117.

Fleet GH. (2003). Yeast interactions and wine flavour. Int J Food Microbiol 86: 11-22.

Fleet GH. (2007). Yeasts in foods and beverages: impact on product quality and safety. Curr Opin Biotechnol 18: 170-175.

Gadanho M, Almeida JM, Sampaio JP. (2003). Assessment of yeast diversity in a marine environment in the south of Portugal by microsatellite-primed PCR. Ant Van Leeuwenhoek 84: 217-227.

Giacometti A, Cirioni O, Fiorentini A, Fortuna M, Scalise G. (1999). Irritable bowel syndrome in patients with Blastocystis hominis infection. Eur J Clin Microbiol Infect Dis 18: 436-439.

Goerges S, Mounier J, Rea MC, Gelsomino R, Heise V, Beduhn $\mathrm{R}$ et al. (2008). Commercial ripening starter microorganisms inoculated into cheese milk do not successfully establish themselves in the resident microbial ripening consortia of a south German red smear cheese. Appl Environ Microbiol 74: 2210-2217.

Hayashi H, Sakamoto M, Benno Y. (2002). Phylogenetic analysis of the human gut microbiota using $16 \mathrm{~S}$ rDNA clone libraries and strictly anaerobic culture-based methods. Microbiol Immunol 46: 535-548.

Ho LC, Armiugam A, Jeyaseelan K, Yap EH, Singh M. (2000). Blastocystis elongation factor-1alpha: genomic organization, taxonomy and phylogenetic relationships. Parasitology 121(Pt 2): 135-144.

Horiki N, Maruyama M, Fujita Y, Yonekura T, Minato S, Kaneda Y. (1997). Epidemiologic survey of Blastocystis hominis infection in Japan. Am J Trop Med Hyg 56: 370-374.

Hugenholtz P, Goebel BM, Pace NR. (1998). Impact of culture-independent studies on the emerging phylogenetic view of bacterial diversity. J Bacteriol 180: 4765-4774.

Kam AP, Xu J. (2002). Diversity of commensal yeasts within and among healthy hosts. Diagn Microbiol Infect Dis 43: 19-28.

Kaneda Y, Horiki N, Cheng XJ, Fujita Y, Maruyama M, Tachibana H. (2001). Ribodemes of Blastocystis hominis isolated in Japan. Am J Trop Med Hyg 65: 393-396.

Karanis P, Kourenti C, Smith H. (2007). Waterborne transmission of protozoan parasites: a worldwide review of outbreaks and lessons learnt. J Water Health 5: $1-38$.

Kelly D, King T, Aminov R. (2007). Importance of microbial colonization of the gut in early life to the development of immunity. Mutat Res 622: 58-69.

Kuhbacher T, Ott SJ, Helwig U, Mimura T, Rizzello F, Kleessen B et al. (2006). Bacterial and fungal microbiota in relation to probiotic therapy (VSL\#3) in pouchitis. Gut 55: 833-841.

Lepere C, Boucher D, Jardillier L, Domaizon I, Debroas D. (2006). Succession and regulation factors of small eukaryote community composition in a lacustrine ecosystem (Lake Pavin). Appl Environ Microbiol 72: 2971-2981.

Lopez-Garcia P, Vereshchaka A, Moreira D. (2007). Eukaryotic diversity associated with carbonates and fluid-seawater interface in Lost City hydrothermal field. Environ Microbiol 9: 546-554.

Madsen AM, Hansen VM, Meyling NV, Eilenberg J. (2007). Human exposure to airborne fungi from genera used as biocontrol agents in plant production. Ann Agric Environ Med 14: 5-24.

Marchesi J, Shanahan F. (2007). The normal intestinal microbiota. Curr Opin Infect Dis 20: 508-513.

Mathieu-Daude F, Welsh J, Vogt T, McClelland M. (1996). DNA rehybridization during PCR: the ' $\mathrm{C}_{\mathrm{o}} \mathrm{t}$ effect' and its consequences. Nucleic Acids Res 24: 2080-2086.

Moon-van der Staay SY, Tzeneva VA, van der Staay GW, de Vos WM, Smidt H, Hackstein JH. (2006). Eukaryotic diversity in historical soil samples. FEMS Microbiol Ecol 57: 420-428.

Muyzer G, de Waal EC, Uitterlinden AG. (1993). Profiling of complex microbial populations by denaturing gradient gel electrophoresis analysis of polymerase chain reaction-amplified genes coding for $16 \mathrm{~S}$ rRNA. Appl Environ Microbiol 59: 695-700.

Ostan I, Kilimcioglu AA, Girginkardesler N, Ozyurt BC, Limoncu ME, Ok UZ. (2007). Health inequities: lower socio-economic conditions and higher incidences of intestinal parasites. BMC Public Health 7: 342 .

Pace NR. (1997). A molecular view of microbial diversity and the biosphere. Science 276: 734-740.

Patterson D. (1994). Progress in Protistology. In: Hausmann $\mathrm{H}$, Hulsmann $\mathrm{N}$ (eds). Proceedings of the IX International Congress of Protozoology. G. Fisher: Berlin, pp 1-14.

Quiros M, Martorell P, Querol A, Barrio E, Peinado JM, de Siloniz MI. (2008). Four new Candida cretensis strains isolated from Spanish fermented sausages (chorizo): taxonomic and phylogenetic implications. FEMS Yeast Res 8: 485-491. 
Rajilic-Stojanovic M, Smidt H, de Vos WM. (2007). Diversity of the human gastrointestinal tract microbiota revisited. Environ Microbiol 9: 2125-2136.

Ranilla MJ, Jouany JP, Morgavi DP. (2007). Methane production and substrate degradation by rumen microbial communities containing single protozoal species in vitro. Lett Appl Microbiol 45: 675-680.

Reddy A, Fried B. (2007). The use of Trichuris suis and other helminth therapies to treat Crohn's disease. Parasitol Res 100: 921-927.

Romano P, Fiore C, Paraggio M, Caruso M, Capece A. (2003). Function of yeast species and strains in wine flavour. Int J Food Microbiol 86: 169-180.

Saitou N, Nei M. (1987). The neighbor-joining method-a new method for reconstructing phylogenetic trees. $\mathrm{Mol}$ Biol Evol 4: 406-425.

Sambrook J, Russell D, Sambrook J, Russell D. (2000). Molecular Cloning: a Laboratory Manual. Cold Spring Harbor Laboratory Press: New York.

Schaffer T, Muller S, Flogerzi B, Seibold-Schmid B, Schoepfer AM, Seibold F. (2007). Anti-Saccharomyces cerevisiae mannan antibodies (ASCA) of Crohn's patients crossreact with mannan from other yeast strains, and murine ASCA IgM can be experimentally induced with Candida albicans. Inflamm Bowel Dis 13: 1339-1346.

Scupham AJ, Presley LL, Wei B, Bent E, Griffith N, McPherson $\mathrm{M}$ et al. (2006). Abundant and diverse fungal microbiota in the murine intestine. Appl Environ Microbiol 72: 793-801.

Silberman JD, Sogin ML, Leipe DD, Clark CG. (1996). Human parasite finds taxonomic home. Nature 380: 398

Song X, Eribe ER, Sun J, Hansen BF, Olsen I. (2005). Genetic relatedness of oral yeasts within and between patients with marginal periodontitis and subjects with oral health. I Periodontal Res 40: 446-452.

Stark D, van Hal S, Marriott D, Ellis J, Harkness J. (2007). Irritable bowel syndrome: a review on the role of intestinal protozoa and the importance of their detection and diagnosis. Int J Parasitol 37: 11-20.
Stensvold CR, Arendrup MC, Jespersgaard C, Molbak K, Nielsen HV. (2007b). Detecting Blastocystis using parasitologic and DNA-based methods: a comparative study. Diagn Microbiol Infect Dis 59: 303-307.

Stensvold CR, Suresh GK, Tan KS, Thompson RC, Traub RJ, Viscogliosi E et al. (2007a). Terminology for Blastocystis subtypes-a consensus. Trends Parasitol 23: 93-96.

Suau A, Bonnet R, Sutren M, Godon JJ, Gibson GR, Collins $\mathrm{MD}$ et al. (1999). Direct analysis of genes encoding $16 \mathrm{~S}$ rRNA from complex communities reveals many novel molecular species within the human gut. Appl Environ Microbiol 65: 4799-4807.

Tamura K, Dudley J, Nei M, Kumar S. (2007). MEGA4: molecular evolutionary genetics analysis (MEGA) software version 4.0. Mol Biol Evol 24: 1596-1599.

Tamura K, Nei M, Kumar S. (2004). Prospects for inferring very large phylogenies by using the neighbor-joining method. PNAS 101: 11030-11035.

Tan KS. (2004). Blastocystis in humans and animals: new insights using modern methodologies. Vet Parasitol 126: $121-144$.

Tan TC, Suresh KG, Thong KL, Smith HV. (2006). PCR fingerprinting of Blastocystis isolated from symptomatic and asymptomatic human hosts. Parasitol Res 99: 459-465.

van Elsas JD, Duarte GF, Keijzer-Wolters A, Smit E. (2000). Analysis of the dynamics of fungal communities in soil via fungal-specific PCR of soil DNA followed by denaturing gradient gel electrophoresis. J Microbiol Methods 43: 133-151.

Yakoob J, Jafri W, Jafri N, Khan R, Islam M, Beg MA et al. (2004). Irritable bowel syndrome: in search of an etiology: role of Blastocystis hominis. Am J Trop Med Hyg 70: 383-385.

Yan Y, Su S, Lai R, Liao H, Ye J, Li X et al. (2006). Genetic variability of Blastocystis hominis isolates in China. Parasitol Res 99: 597-601.

Yoshikawa H, Abe N, Wu Z. (2004). PCR-based identification of zoonotic isolates of Blastocystis from mammals and birds. Microbiology 150: 1147-1151.

Supplementary Information accompanies the paper on The ISME Journal website (http://www.nature.com/ismej) 